\title{
Response to the World Health Organization's working document for the development of a global action plan to reduce alcohol-related harm: Position Statement of the Hong Kong Alliance for Advocacy Against Alcohol
}

This article was published on $1 \mathrm{Feb}$ 2021 at www.hkmj.org.
Regina CT Ching *, FHKAM (Community Medicine), MScPHM LSHTM (Lond), SP Mak, FHKAM (Community Medicine), FFPH, Martin CS Wong ${ }^{1}$, MD, MPH, Ming Lam, FHKAM (Psychiatry), MRCPsych, WM Chan, FHKAM (Community Medicine), Margaret FY Wong, DSW, MSocSci, Raymond Liang, MD, FRCP, TH Lam², MD, Hon FHKCCM; for the Hong Kong Alliance for Advocacy Against Alcohol ${ }^{\dagger}$

${ }^{1}$ JC School of Public Health and Primary Care, Faculty of Medicine, The Chinese University of Hong Kong, Hong Kong

${ }^{2}$ Emeritus Professor, Hon Clinical Professor, School of Public Health, The University of Hong Kong, Hong Kong

* Corresponding author: reginachingching@hotmail.com

† The Hong Kong Alliance for Advocacy Against Alcohol was established under the Hong Kong College of Community Medicine

https://doi.org/10.12809/hkmj215109

\section{Background}

Globally, alcohol use accounts for approximately 3 million deaths every year and the overall burden of disease and injuries remains high. Health consequences aside, alcohol use incurs significant social and economic losses relating to the justice sector, workforce productivity and unemployment, and pain and suffering of the drinker and other people.

In May 2010, the 63rd World Health Assembly endorsed the Global Strategy to Reduce the Harmful Use of Alcohol (Resolution WHA63.13). The Global Strategy gives a strong mandate to the World Health Organization (WHO) to strengthen action at national, regional and global levels and envisions improved health and social outcomes for individuals, families and communities, with considerably reduced morbidity and mortality due to alcohol use and its ensuing social consequences.

Despite adoption of the political declarations emanating from high-level meetings of the United Nations General Assembly on noncommunicable diseases in 2011; inclusion of alcohol for prevention and treatment of substance abuse in target 3.5 of the Sustainable Development Goals 2030; introduction of the WHO Global Action Plan for the Prevention and Control of NCDs 2013-2020 (subsequently extended to 2030 to align with the Sustainable Development Goals 2030) and updated evidence on a prioritised set of cost-effective or 'best-buy' policy measures known as the SAFER initiative, implementation of the Global Strategy worldwide has been uneven, and resources and capacities falling behind the magnitude of the problems. The Global Strategy has not resulted in considerable reductions in alcohol-related morbidity and mortality and the ensuing social consequences. The levels of alcohol consumption and alcohol-attributable harm continue to be unacceptably high.

On this basis, the WHO Executive Board in 2020 requested the WHO Director-General, inter alia, "to develop an action plan (2022-2030) to effectively implement the Global Strategy to reduce the harmful use of alcohol(https://cms.who.int/teams/ mental-health-and-substance-use/alcohol-drugsand-addictive-behaviours/alcohol/global-alcoholstrategy) as a public health priority, in consultation with relevant stakeholders, for consideration by the 75th World Health Assembly in 2022". The WHO Secretariat conducted a web-based consultation (https://www.who.int/news-room/articles-detail/ global-action-plan-to-reduce-the-harmful-use-ofalcohol) from 16 November to 13 December 2020 on a working document for development of the action plan open to Member States, United Nations organisations and other international organisations, and non-State actors. All relevant feedback received will be published on the WHO website.

The Hong Kong Alliance for Advocacy Against Alcohol (HKAAAA) was established under the Hong Kong College of Community Medicine in 2015 and comprises individuals from the academic, medical and health, social, and education sectors, to advocate for effective evidence-based policies and actions to reduce alcohol-related harms in Hong Kong. The HKAAAA submitted the following Position Statement in response to the WHO consultation. 


\section{Position statement}

The HKAAAA has read the working document for development of an action plan to strengthen implementation of the Global Strategy to reduce the harmful use of alcohol and has the following comments and suggestions:

1. The HKAAAA welcomes WHO's move to develop an action plan to strengthen the Global Strategy to reduce harms related to alcohol use.

2. The HKAAAA understands the Global Strategy was set out to support and complement public health policies in Member States at national and local levels to achieve considerable reduced morbidity and mortality as well as improved health and social outcomes for individuals, families and communities, but notes that globally, the levels of alcohol consumption and alcoholattributable harm continue to be unacceptably high.

3. The HKAAAA agrees that considerable challenges for the development and implementation of effective alcohol policies relate to the complexity of the problem, differences in cultural norms and contexts, intersectoral nature of cost-effective solutions and limited political will and government leadership, but considers the influence of powerful commercial interests especially from transnational alcohol companies to be exerting the greatest negative influence of all.

4. Economic operators with core roles as developers, producers, distributors, marketers and sellers of alcoholic beverages, have primary commercial responsibilities to their shareholders and must therefore rely on substantial sales either by encouraging heavy drinking or engaging more people to drink, many of whom belong to vulnerable and marginalised groups such as young people, less educated, unemployed, people who are stressed out or suffer from mental ill health, and so on. As such, economic operators have mission and vision that fundamentally conflict with those of the Global Strategy. The HKAAAA is of the view that these economic operators should have no role in developing or influencing the formulation of this action plan, or for that matter, development, implementation and evaluation of alcohol policy at global, national and local levels. These economic operators are not, and should not be construed as, equivalent to other 'non-state actors' in the context of the action plan. Neither is there a need to 'invite' them to self-regulate or act contrary to their profit-driven goals and objectives.

5. As WHO rightly points out, alcohol remains the only psychoactive and dependence-producing substance that exerts a significant impact on global population health that is not controlled at the international level by legally binding regulatory instruments. The HKAAAA urges WHO to set out in the action plan immediate, concrete steps and timeline to formulate a global normative law on alcohol at the intergovernmental level, modelled on the WHO Framework Convention on Tobacco Control, to regulate the distribution, sale and marketing of alcohol within the context of international, regional and bilateral trade negotiations, as well as to protect the development of alcohol policies from interference by transnational corporations and commercial interests.

6. The launching of WHO's SAFER initiative comprising the most cost-effective actions or "best buys", namely, increasing taxes on alcoholic beverages, enacting and enforcing bans or comprehensive restrictions on exposure to alcohol advertising across multiple types of media, and enacting and enforcing restrictions on the physical availability of retailed alcohol, is applauded. However, the HKAAAA considers that political will, government leadership and intergovernmental commitment aside, interference from transnational commercial interests needs to be kept at bay, through global regulatory efforts initiated, coordinated and assured by WHO.

7. The HKAAAA recognises that in today's world that favours free trade, a legally binding regulatory framework provides the bottom line for economic operators in alcohol production and trade as well as operators in other relevant sectors to eliminate marketing and advertising of alcoholic products to minors and other vulnerable groups, prevent heavy drinking, eliminate false health claims, and ensure availability of easily understood consumer information on the labels of alcoholic beverages (including composition, age limits, health warning and contra-indications for alcohol use).

8. The HKAAAA further points out the term "harmful use of alcohol" used repeatedly throughout the consultation document implies there are beneficial uses of alcohol, which practically do not exist. This misperception is, to a large extent, influenced and reinforced by commercial messaging and poorly regulated alcohol marketing which deprioritise efforts to counter the harms of alcohol use. This has resulted in low awareness and poor acceptance of the overall negative impact of alcohol consumption on a population's health, safety and wellness among 
decision-makers, general public and even healthcare providers. Moreover, it confuses the public and hinders education efforts. The HKAAAA calls on WHO to stop using the term "harmful use of alcohol" and adopt "alcohol-related harm" in its place.

9. To reduce interference from commercial interests, the HKAAAA calls on all types of dialogue between economic operators with a stake in alcohol and public institutions (WHO secretariat, Member States, public funded bodies and research institutions, and civil societies) be halted and reduced to a minimum, and if they must go ahead, be documented with respect to the purpose, parties involved, mode, content, expenses and outcome for the sake of transparency and public accountability.

10. To help expose and recognise pervasive commercial interference in public policy making and anti-alcohol efforts including 'corporate social responsibility' initiatives at transnational, national and local levels in order that public and non-profit organisations may steer clear of commercial interests of economic operators, the HKAAAA requests the WHO to take the lead in a global stock taking exercise that will also serve as baseline for future regulatory work.

11. The HKAAAA recommends the setting of SMART (specific, measurable, achievable, relevant and time-bound) objectives relating to all recommended or proposed action within the action plan.

12. The HKAAAA suggests biennial publishing of national status reports on alcohol and health, and biennial reporting by action parties to help focus global, national and local anti-alcohol efforts, and strengthen monitoring and public accountability.

13. To counteract alcohol marketing in the form of recurrent wine and dine promotions, sports sponsorships and the like, which are often held for days and weeks in a row, HKAAAA supports the WHO to initiate global efforts to organise annual national alcohol awareness drives. HKAAAA, however, considers these drives should last for at least 5 to 7 days, and incorporate health behaviour changes on top of raising awareness. Examples may include public and nonpublic institutions refraining from serving alcohol at business and private occasions, making pledges to reject alcohol sponsorships, and strengthening support for drinkers who anticipate quitting.

\section{Concluding remarks}

Alcohol is a toxic substance with dependence producing properties, contributing to 3 million deaths and $5.1 \%$ of disease burden every year globally. It is time the health and social damage of drinking be fully recognised and effectively dealt with at global, national and health systems levels, modelled on the WHO Framework Convention on Tobacco Control.

\section{Author contributions}

All authors contributed to the editorial, approved the final version for publication, and take responsibility for its accuracy and integrity.

\section{Conflicts of interest}

All authors have disclosed no conflict of interest.

\section{Declaration}

This Position Statement was submitted in response to the World Health Organization (WHO) online consultation on a working document on developing a global action plan to reduce the harmful use of alcohol (https://www.who.int/ news-room/articles-detail/global-action-plan-to-reducethe-harmful-use-of-alcohol). Relevant submissions will be published on the WHO website in mid-February 2021.

\section{Funding/support}

This editorial received no specific grant from any funding agency in the public, commercial, or not-for-profit sectors. 